\title{
Intermittent ischaemic arrest and cardioplegia in coronary artery surgery: coming full circle?
}

\author{
D P Taggart, S Bhusari, J Hooper, M Kemp, P Magee, J E Wright, R Walesby
}

\begin{abstract}
Objective-To compare the cardioprotective efficacy of cold crystalloid cardioplegia and intermittent ischaemic arrest in patients undergoing elective coronary artery surgery.

Design-Prospective randomised trial. Setting-London teaching hospital.

Subjects-20 patients with at least moderately good left ventricular function undergoing elective coronary artery surgery by one experienced surgeon and needing at least two bypass grafts.

Interventions-Patients were randomised to cold crystalloid cardioplegia or intermittent ischaemic arrest. Main outcome measures-The primary determinant of the efficacy of myocardial protection was serial measurement (before and at 1, 6, 24, and 72 hours after the end of cardiopulmonary bypass) of cardiac troponin $\mathbf{T}$ (cTnT), a highly sensitive and specific marker of myocardial damage.
\end{abstract}

Results-There was no significant difference in age, ejection fraction, number of grafts, bypass times, or cross clamp times between the two groups. One patient in the cardioplegia group had a perioperative infarct and was excluded from further study. In both groups there was a significant increase in cTnT, with peak concentrations being reached 6 hours after the end of cardiopulmonary bypass and remaining significantly high at 72 hours. At 6 hours the median $\mathbf{7 5 \%}$ interquartile range) concentrations of cTnT were similar in both groups $(1.8$ $(1 \cdot 0-3 \cdot 6) \mu \mathrm{g} / 1$ for cardioplegia $v \quad 1.9$ $(1 \cdot 0-3 \cdot 5) \mu \mathrm{g} / 1$ for intermittent ischaemic arrest).

Conclusion-This trial shows that intermittent ischaemic arrest, even without systemic cooling or venting of the left ventricle, provides a similar level of myocardial protection to cardioplegia in patients with moderate left ventricular function and short ischaemic times.

(Br Heart f 1994;72:136-139)

Successful coronary artery revascularisation is dependent on technical excellence and effective myocardial protection during surgery. Cold crystalloid cardioplegia is widely perceived to provide more effective myocardial protection than intermittent ischaemic arrest and in the past decade more than $90 \%$ of surgeons have adopted its use for myocardial preservation during coronary revascularisation. ${ }^{12}$

There have, however, been few randomised clinical trials comparing cardioplegic and non-cardioplegic techniques for myocardial protection during coronary artery surgery and these have not provided conclusive evidence of the superiority of either technique. ${ }^{23}$ Consequently most experienced surgeons still use intermittent ischaemic arrest for coronary revascularisation when the aorta is alternatively clamped for brief periods (usually up to 15 minutes) during construction of each distal anastomosis and then partially occluded with a side biting clamp during construction of the proximal anastomosis. Its proponents argue that it is a more versatile technique, allows better judgement of where to open diseased arteries, and optimises judgement of the length and orientation of grafts. It does not have the disadvantages of uneven myocardial distribution of cardioplegia through heavily diseased or blocked coronary arteries ${ }^{45}$ or washing out of cardioplegia by non-coronary collateral flow. ${ }^{6}$ Furthermore, its advocates point to the excellent clinical results from this technique. $^{78}$

Cardiac troponin $\mathrm{T}$ (cTnT) is derived from the troponin regulatory complex on the thin filament of the myocardial contractile apparatus. Because the cardiac isoform is distinct from the skeletal muscle isoform ${ }^{9}$ cTnT specifically identifies myocardial damage in a variety of clinical settings. ${ }^{10-14}$ Its cardiac specificity makes it a particularly useful marker for assessing myocardial damage during cardiac surgery ${ }^{14}$ by contrast with myoglobin and the MB isoenzyme of creatine kinase that may also be derived from skeletal muscle after cardiac operations. ${ }^{15}$ A serum cTnT concentration $>0.2 \mu \mathrm{g} / 1$ detects myocardial injury whereas a value $<2.5 \mu \mathrm{g} / 1$ excludes "significant" myocardial injury. ${ }^{13}$

To compare the effects of cold crystalloid cardioplegia and intermittent ischaemic arrest on myocardial preservation 20 patients undergoing coronary artery surgery were randomised to either technique. Efficacy of myocardial protection was assessed by clinical course, electrocardiographic changes, and serial measurements of $\mathrm{cTnT}$.

\section{Patients and methods \\ PATIENTS}

We studied 20 patients undergoing elective coronary surgery. To keep the group as 
Clinical characteristics mean (SD) of the two groups

\begin{tabular}{lll}
\hline & Cardioplegia & $\begin{array}{l}\text { Ischaemic } \\
\text { arrest }\end{array}$ \\
\hline No & 10 & 10 \\
Age (yr) & $59(8)$ & $61(8)$ \\
Ejection fraction (\%) & $51(8)$ & $51(9)$ \\
Grafts (n) & $3.0(0 \cdot 9)$ & $2.9(0 \cdot 6)$ \\
Ischaemic time (min) & $30(9)$ & $32(5)$ \\
Cardiopulmonary bypass & $58(17)$ & $64(10)$ \\
time (min) & $7(1)$ & $7(0 \cdot 4)$ \\
Hospital stay (days) & &
\end{tabular}

homogeneous as possible we excluded patients who were aged over seventy, had unstable symptoms, who needed emergency surgery, had ejection fractions $<30 \%$, or required endarterectomy or combined procedures.

\section{RANDOMISATION}

Patients were allocated to cardioplegia or intermittent ischaemic arrest by a computer generated program.

\section{SURGERY}

All operations were performed by one surgeon (RW) equally practiced in both techniques. Cardiopulmonary bypass was performed with non-pulsatile flow at $2.4 \mathrm{l} / \mathrm{square}$ metre of body surface area/min. With intermittent ischaemic arrest the body temperature was allowed to drift to $34^{\circ} \mathrm{C}$ (no active cooling was used) and the coronary anastomoses performed during brief periods (about 10-15 $\mathrm{min}$ ) of aortic clamping and fibrillation. During each proximal anastomosis the heart was reperfused. No direct or indirect left ventricular venting was used.

Patients randomised to cardioplegia received 11 of St Thomas's Hospital formula cardioplegic solution at $4^{\circ} \mathrm{C}$ (containing $3.253 \mathrm{~g}$ magnesium chloride, $1.193 \mathrm{~g}$ potassium chloride, $272.8 \mathrm{mg}$ procaine hydrochloride, $0.01 \%$ weight/volume disodium edetate)

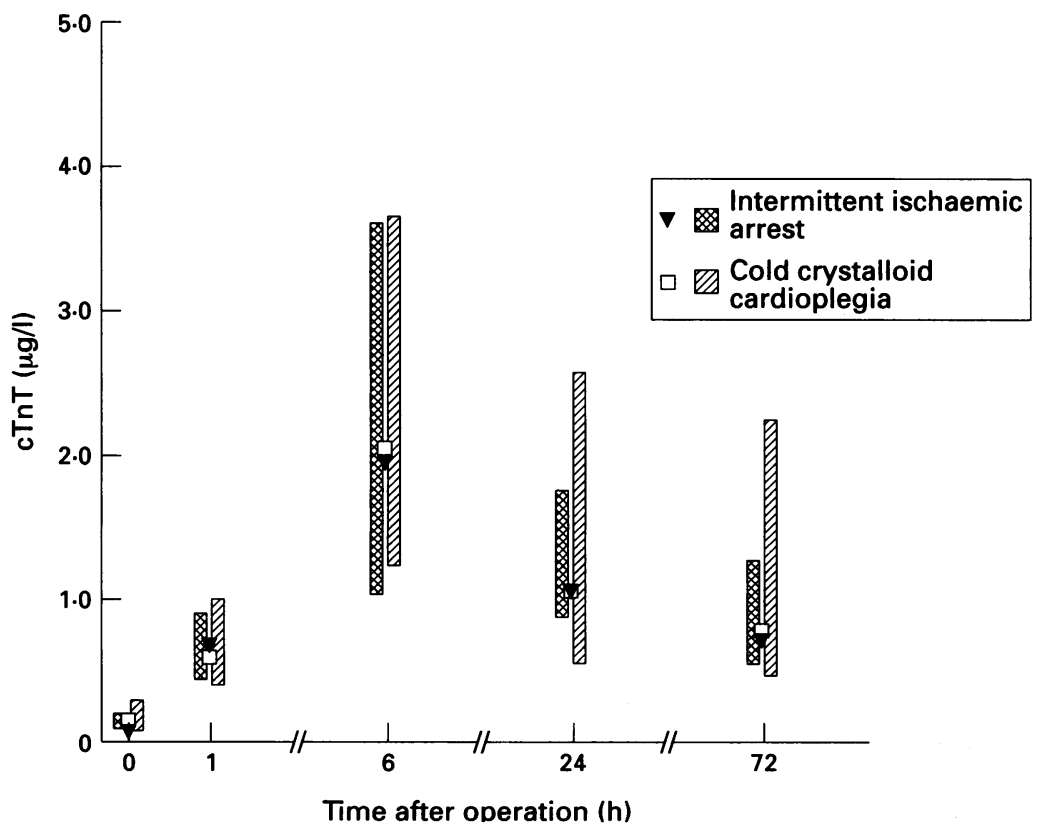

Cardiac troponin $T$ concentration in both groups, shown as median (25-75\% range). infused into the aortic root. Systemic hypothermia of $28^{\circ} \mathrm{C}$ to $30^{\circ} \mathrm{C}$ was used while the distal anastomoses were completed under one period of arrest.

\section{BLOOD SAMPLES}

Blood samples for measurement of cTnT were taken before and at one, six, 24 , and 72 hours after the end of cardiopulmonary bypass. Samples were collected into lithium heparin tubes and centrifuged within $30 \mathrm{~min}$ utes. The plasma was separated from the cells and stored at $-20^{\circ} \mathrm{C}$ until analysis.

\section{BIOCHEMICAL ANALYSES}

Cardiac troponin $T$ was measured by an enzyme linked immunosorbent assay (ELISA) technique (Elisa Troponin T Kit, Boehringer Mannheim UK, Lewes, UK). Assay imprecision, expressed as a coefficient of variation, was $4.3 \%$ at a plasma cTnT concentration of $4 \cdot 8 \mu \mathrm{g} / 1$ and $12 \cdot 9 \%$ at a plasma cTnT concentration of $0.2 \mu \mathrm{g} / \mathrm{l}$.

ELECTROCARDIOGRAPHIC DIAGNOSIS OF MYOCARDIAL INFARCTION

Serial electrocardiograms were performed before and one, six, 24, and 72 hours after surgery. A new $Q$ wave ( $>0.04 \mathrm{~ms}$ ) or loss of $>25 \%$ of $R$ waves in at least two leads were considered diagnostic of infarction. Minor ST-T wave changes and changes in conduction were not, by themselves, considered diagnostic of myocardial infarction.

\section{STATISTICAL ANALYSES}

Patient data are presented as mean (SD). Biochemical data are presented as median (75\% interquartile range). Serial changes within and between the groups were compared with the Wilcoxon rank sum test.

\section{Results}

The study comprised 20 patients randomised to cardioplegia or intermittent ischaemic arrest during elective coronary artery surgery by one surgeon. The groups were well matched with respect to age, ejection fraction, number of grafts, ischaemic and bypass times (table).

One patient in the cardioplegia group had a perioperative infarct on electrocardiographic and biochemical grounds. This patient developed a new q wave on electrocardiography accompanied by large increases in cTnT $(>10 \mu \mathrm{g} / 1)$ and creatine kinase-MB isoenzyme $(>300 \mu \mathrm{g} / 1)$. This patient's data have not been included in the diagram comparing cTnT concentrations between the groups.

The figure shows that there was a highly significant $(p<0.001)$ increase in cTnT concentration one hour after the end of cardiopulmonary bypass and cTnT continued to increase to peak values at the sixth hour after operation. The peak median $(75 \%$ interquartile range) concentrations of c TnT were similar in both groups $(1.8(1.0-3.6) \mu \mathrm{g} / 1$ for cardioplegia $v 1.9(1.0-3.5) \mu \mathrm{g} / 1$ for intermittent ischaemic arrest). At 72 hours cTnT concen- 
trations were still significantly raised and similar in both groups $(0.6(0.4-1.3) \mu \mathrm{g} / 1$ for cardioplegia $v \quad 0.65 \quad(0.5-1 \cdot 2) \mu \mathrm{g} / 1$ for intermittent ischaemic arrest). There was no significant difference in cTnT concentrations between the groups at any time.

With the exception of the single patient with a perioperative infarct serial electrocardiograms after the operation only showed occasional minor ST-T wave changes. The patient with the perioperative infarct remained clinically well and was discharged on the eighth postoperative day. All other patients had an uneventful recovery and were discharged home on the seventh or eighth postoperative day.

\section{Discussion}

Cardiac arrest with antegrade cold crystalloid cardioplegia is currently the most widely used technique for myocardial protection during coronary artery surgery. ${ }^{12}$ Attempts to improve both the composition of cardioplegia and its distribution through diseased coronary vessels has led to increasingly elaborate modifications including cold blood cardioplegia given antegradely through the aortic $\operatorname{root}^{16}$ or retrogradely through the coronary sinus, ${ }^{17}$ substrate enrichment with glutamate, ${ }^{18}$ a warm infusion of cardioplegia "hot shot" before removal of the cross clamp, ${ }^{19}$ and most recently the use of warm blood cardioplegia. ${ }^{2021}$

There is, however, little clinical evidence to justify these increasingly complex techniques except in repeat coronary surgery (where retrograde cardioplegia may reduce the risk of embolisation from diseased grafts). The supposed superiority of the newer techniques over antegrade cold crystalloid cardioplegia has been shown in laboratory experiments and in retrospective and non-randomised studies. Such studies are notoriously unsound. Since 1980 only two clinical trials have compared cardioplegia and intermittent ischaemic arrest in a prospective, randomised, manner. Pepper and colleagues randomised 50 patients to cardioplegia or intermittent ischaemic arrest at $32^{\circ} \mathrm{C}$ and found no significant difference in myocardial protection but extrapolated the data to suggest that cardioplegia might confer greater benefit for longer ischaemic periods. ${ }^{2}$ Flameng and colleagues randomised 72 patients to intermittent ischaemic arrest at $25^{\circ} \mathrm{C}$, intermittent ischaemic arrest at $32^{\circ} \mathrm{C}$, or to cardioplegia. The intermittent ischaemic arrest groups showed fewer rhythm disturbances whereas the cardioplegia group showed better early functional recovery (probably by improved preservation of high energy phosphates). ${ }^{3}$ There was, however, no significant difference in the release of creatine kinase $\mathrm{MB}$ isoenzyme between the groups. ${ }^{3}$

Serial measurements of cTnT in our trial show that cardioplegia and intermittent ischaemic arrest provide a similar degree of myocardial protection. The cTnT concentrations are similar to those we found in another series of patients undergoing coronary surgery with intermittent ischaemic arrest, ${ }^{14}$ and the peak concentrations of $<2.5 \mu \mathrm{g} / 1$ in both groups probably rule out any noteable myocardial damage. ${ }^{13}$

Two notes of caution are warranted. Firstly this trial contains only a few patients and raises the possibility of a type 2 statistical error. We think this is unlikely in view of the sensitivity and specificity of cTnT and the qualitative and quantitative similarity of the cTnT response in both groups. Indeed, based on our results, to detect a $20 \%$ reduction in peak cTnT with cardioplegia with a power of $80 \%$ at the $5 \%$ level of significance would require randomisation of 240 patients (Dr A Bowman, Department of Statistics, Glasgow University, personal communication).

Secondly, our trial only examined myocardial protection in patients with relatively short cross clamp times and at least moderately good left ventricular function. It is not clear from our study how intermittent ischaemic arrest would compare with cardioplegia in patients with longer cross clamp times or severely impaired left ventricular function.

Our study implies that intermittent ischaemic arrest provides a similar level of myocardial protection to cardioplegia when ischaemic times are short and is consistent with the clinical results reported by advocates of non-cardioplegic myocardial revascularisation. ${ }^{7}$ In a consecutive series of 3000 patients undergoing primary coronary revascularisation with intermittent ischaemic arrest the mortality for elective operation was $0.5 \%$ with an overall mortality of $1.47 \%$ (including $30 \%$ of patients who were aged $>70,10 \%$ with ejection fractions $<30 \%$, and $31 \%$ with unstable angina). Although our study excluded patients with severe left ventricular impairment Boncheck and colleagues have emphasised the advantages of intermittent ischaemic arrest in such patients; in their consecutive series of 290 patients with an ejection fraction of $<30 \%$ the mortality was $6 \cdot 2 \%{ }^{8}$

There are sound physiological reasons why intermittent ischaemic arrest might provide effective myocardial protection. Murray and colleagues described the phenomenon of ischaemic "preconditioning" when they showed that a brief period of ischaemia followed by a brief period of reperfusion made the heart more resistant to a subsequent lengthier period of ischaemia. ${ }^{22}$ Preconditioning has now been shown in animal species and although the exact mechanism is uncertain ${ }^{23}$ there is increasing evidence that it is an adenosine mediated effect through $A_{1}$ receptors. ${ }^{24}$ Preconditioning of myocardium during coronary artery surgery with intermittent ischaemic arrest has recently been shown to result in better preservation of ATP during subsequent periods of ischaemia. $^{25}$

Our technique of intermittent ischaemic arrest is simpler than that usually described. ${ }^{1-378}$ It relies on venous drainage through a two stage atrial cannula and aortic return without venting of the left ventricle (thereby minimising the chance of air 
embolism). Furthermore the systemic temperature is merely allowed to drift to $34^{\circ} \mathrm{C}$ without active cooling or topical hypothermia. There are, however, potential limitations of intermittent ischaemic arrest: it is contraindicated in patients with extensive calcific degeneration of the aorta where repeat clamping might precipitate dissection or embolisation of particulate debris. In patients undergoing repeat coronary revascularisation where there are heavily diseased but patent grafts, retrograde cardioplegia, at least theoretically, reduces the risk of embolisation. Finally, because of a greater pressure for relatively speedy completion of distal anastomoses with intermittent ischaemic arrest this technique is not ideal for the training of junior cardiac surgeons.

In conclusion this study shows that intermittent ischaemic arrest provides equivalent myocardial protection to cold crystalloid cardioplegia in patients with moderate left ventricular function undergoing first time coronary artery surgery with short ischaemic times. Furthermore in such patients systemic hypothermia to less than $34^{\circ} \mathrm{C}$ and the use of left ventricular venting seem unnecessary adjuncts to intermittent ischaemic arrest.

1 Miller DW Jr, Ivey TD, Bailey WW, Hessel EA. The practice of coronary artery bypass surgery in 1980 . $\mathcal{F}$ Thorac Cardiovasc Surg 1981;81:423-8.

2 Pepper JR, Lockey E, Cankovic-Darracott S, et al. Cardioplegia versus intermittent ischaemic arrest in coronary bypass surgery. Thorax 1982;37:887-92.

3 Flameng W, Van der Vusse GJ, de Meyere R, et al. Intermittent aortic cross-clamping versus St Thomas' Hospital Cardioplegia in extensive aorto-coronary bypass grafting. A randomized clinical study. $\mathcal{F}$ Thorac Cardiovasc Surg 1984;88:164-73.

4 Hilton CJ, Treuble W, Acker M, et al. Inadequate cardioplegic protection with obstructed coronary arteries. Ann Thorac Surg 1979;28:323-34.

5 Grondin CM, Helias J, Vouhe PR, Robert P. Influence of a critical coronary artery stenosis on myocardial protection critical coronary artery stenosis on myocardial protection through cold potassium cardic

6 Hetzer R, Warnecke H, Wittrock H, Engel HJ, Borst HG. Extracoronary collateral myocardial blood flow during cardioplegic arrest. Thorac Cardiovasc Surg 1980;28: 191-6.
7 Akins W. Noncardioplegic myocardial preservation for coronary revascularization. If Thorac Cardiovasc Surg 1984;88:174-81.

8 Bonchek LI, Burlingame MW, Vazales BE, Lundy EF, Gassmann CJ. Applicability of noncardioplegic coronary bypass to high-risk patients. Selection of patients, technique and clinical experience in 3000 patients. $\mathcal{F}$ Thorac Cardiovasc Surg 1992;103:230-7.

9 Wilkinson JM, Grand RJ. Comparison of amino acid sequence of troponin $T$ from different striated muscles. Nature 1987;271:31-5.

10 Katus HA, Schoeppenthau M, Tanzeem A, et al. Noninvasive assessment of perioperative myocardial cell invasive assessment of perioperative myocardial cell damage by circulati

11 Hamm CW, Ravkilde J, Gerhardt W, et al. The prognostic value of serum troponin $\mathrm{T}$ in unstable angina. $N$ Engl $\mathcal{F}$ Med 1992;327:146-50.

12 Donnelly $R$, Hillis WS. Cardiac troponin T. Lancet 1993;341:410-1.

13 Mair P, Mair J, Koller J, Wieser C, Artner-Dworzak E, Puschendorf B. Cardiac troponin T in the diagnosis of heart contusion. Lancet 1991;338:693.

14 Taggart DP, Young V, Hooper J, et al. Lack of cardioprotective efficacy of allopurinol in coronary artery surgery. Br Heart $\mathcal{F} 1994 ; 71: 177-81$.

15 Seguin J, Saussine M, Ferriere M, et al. Comparison of myoglobin and creatine kinase $M B$ levels in the evaluation of myocardial injury after cardiac operation. I Thorac Cardiovasc Surg 1988;95:294-7.

16 Follette DM, Mulder DG, Maloney JV, Buckberg GD. Advantages of blood cardioplegia over continuous perfusion or intermittent ischaemia. 7 Thorac Cardiovasc Surg 1978;76:604-17.

17 Menasche P, Kural S, Fauchet M, et al. Retrograde coronary sinus perfusion: a safe alternative for ensuring cardioplegic delivery in aortic valve surgery. Ann Thorac Surg 1982;34:645-57.

18 Rosenkrantz ER, Buckberg GD, Laks H, Mulder DG. Warm induction of cardioplegia with glutamateenriched blood in coronary patients with cardiogenic shock who are dependent on inotropic drugs and intraaortic balloon support. $\mathcal{F}$ Thorac Cardiovasc Surg

19 Teoh KH, Christakis GT, Weisel RD, et al. Accelerated myocardial metabolic recovery with terminal warm blood cardioplegia. F Thorac Cardiovasc Surg 1986;91: 888-95.

20 Lichenstein SV, Ashe KA, El Dalati H, Cusimano RJ, Panos A, Slutsky AS. Warm heart surgery. $\mathcal{F}$ Thorac Cardiovasc Surg 1991;101:269-74.

21 Salerno TA, Houck JP, Barrozo CA, et al. Retrograde continuous warm blood cardioplegia: a new concept in myocardial protection. Ann Thorac Surg 1991;51:245-7.

22 Murray CE, Jennings RB, Reimer KA. Preconditioning with ischemia: a delay of lethal cell injury in ischemic myocardium. Circulation 1986;74:1124-36.

23 Murray CE, Jennings RB, Reimer KA. New insights into potential mechanisms of ischemic preconditioning. Circulation 1991;84:442-5.

24 Liu GS, Thornton T, Van Winkle DM, Stanley AW, Olsson RA, Downey JM. Protection against infarction afforded by preconditioning is mediated by $\mathrm{Al}$ adeno-

25 Yellon DM, Alkhulaifi AM, Pugsley WB. Preconditioning the human myocardium. Lancet 1993;342:276-7. 